\title{
Commentary
}

\section{Formalized Curiosity: Reflecting on the Librarian Practitioner-Researcher}

\author{
Virginia Wilson \\ Librarian, Murray Library \\ University of Saskatchewan \\ Saskatoon, Saskatchewan, Canada \\ Email: virginia.wilson@usask.ca
}

Received: 3 Feb. 2013
Accepted: 21 Feb. 2013

(c) 2013 Wilson. This is an Open Access article distributed under the terms of the Creative Commons-AttributionNoncommercial-Share Alike License 2.5 Canada (http://creativecommons.org/licenses/by-nc-sa/2.5/ca/), which permits unrestricted use, distribution, and reproduction in any medium, provided the original work is properly attributed, not used for commercial purposes, and, if transformed, the resulting work is redistributed under the same or similar license to this one.

\section{Introduction}

Research is formalized curiosity. It is poking and prying with a purpose.

Zora Neale Hurston (1942)

There's a well-documented gap between research and practice. A Google search for scholarly articles using the term "research practice gap" yields 2,530 hits as of this writing, while a search using the discovery layer at the University Library, University of Saskatchewan, for the same search terms yields 1,038 hits. There are a large number of articles which explore bridging the research/practice gap. So what will fill that gap in librarianship? Partnerships between LIS scholars and librarians have been suggested, and this can certainly help to mitigate the research/practice gap. Each group has things that the other group needs. Practitioners often have funding barriers, a real or perceived lack of research skills, and uneven access to the research literature. Scholars have less access to certain data that can only be obtained from practice situations, and a partnership with library practitioners can provide greater access to real life locations, users, and situations. As well, a partnership can help ensure that what the scholars are researching is relevant to the practitioners. However, scholar/practitioner partnerships sometimes are not practical, even in our age of social networking. In Canada, for example, there is a dearth of library schools to cover our vast physical space. Physical proximity can play a role in whether or not a partnership is successful. Timeliness also is a factor. Practitioners sometimes need to "hit the ground running" and get their research done in order to inform practice. The logistics of a partnership can be time-consuming. As well, I am estimating that there are far more library and information professionals than there are university library scholars, so it's really up to us to fill that gap ourselves in many cases.

That is where the notion of the practitionerresearcher comes in. This is not a new concept. Healthcare, education, and social work to 
name just three, have a history with the practitioner-researcher. The literature in these areas is filled with examples, dilemmas, problems, solutions, and illustrations of the practitioner-researcher model. And given that evidence based library and information practice (EBLIP) encourages practitioner research (see Crumley and Koufogiannakis (2002) for their practical definition of EBLIP), one of the next steps for EBLIP is to turn attention to the librarian practitionerresearcher as an encouraged and formalized role. Not every information professional will conduct research, just as not every nurse, social worker, or teacher conducts research. But many will, and the rest of us will use this research in its various forms. Organizational supports are needed to legitimize this role and to reinforce its necessity in library practice.

\section{Practitioner-Researcher: Definitions}

So what is a practitioner-researcher? The simplest definition would be that it is a practitioner who conducts research. In fact, Peter Jarvis, who wrote the seminal book on the subject, The practitioner-researcher: Developing theory from practice defines it as just that: "practitioners who do research" (Jarvis, 1999 p. 3). Cochran-Smith and Lytle define teacher research as "systematic, intentional inquiry by teachers" (1990, p. 2). Shaw, who writes about the practitioner-researcher in a social work context, claims that "it is not adequate to define practitioner research simply as research carried out by practitioners without grounding it on the basis of purpose." (2005, p. 1232). He prefers McLeod's definition, which states that practitioner research is "research carried out by practitioners for the purpose of advancing their own practice" (Shaw, 2005, p. 1232). Although McLeod is referring to practitioner research, I would say the same thing about the practitioner-researcher to a certain extent. Practitioner-researchers largely conduct research to inform their own practice and to make decisions around practice issues. Shaw defines practitioner involvement in research as the "evaluation, research, development, or more general inquiry that is small scale, local, grounded, and carried out by professionals who directly deliver those self-same services" (2005, 1232). In the health context, Yanos and Ziedonis's definition of a clinician-researcher is "an individual who both conducts research and provides direct services" (2006, p. 249), just like librarians who are practitionerresearchers. Bentz and Shapiro talk about the scholarly practitioner in their book Mindful inquiry in social research and define it as "someone who mediates between her professional practice and the universe of scholarly, scientific, and academic knowledge and discourse. She sees her practice as part of a larger enterprise of knowledge generation and critical reflection" (1998, p. 66).

This is my view of what a practitionerresearcher is: rather than being on the outside looking in, the practitioner-researcher is someone on the inside looking around, observing and attempting to understand what's going on for the benefit of how things are working on the inside. It is the practitioner reflecting on practice, being curious about practice in a formalized way, and wanting to know more about practice in order to make that practice better.

Jarvis (2000), via Watson-Boone, describes three types of practitioner-researchers:

1. Those who undertake formal or continuing education that includes "studying one or more aspects of their practice" (p. 85). An example would be a librarian who decides to do the $\mathrm{PhD}$ and chooses topics from her practice to delve into.

2. Those who carry out projects to inform policy decisions. An example would be librarians who conduct research to consider new approaches to library services.

3. Those who do research to satisfy their own curiosity. For example, academic librarians who continue their research after getting tenure because they are interested in the topic.

Watson-Boone writes a powerful statement that to me gets to the nub of the practitionerresearcher: "Practitioner-researchers believe 
that continuous learning about their practice is fundamental to understanding and adapting themselves and their work to changing work requirements and that without such learning one cannot maintain a specialty or be an expert" (2000, p. 86). She also states that "within academic librarianship, it may be that the major difference between being a practitioner and being a practitionerresearcher is not one's publication rate, but rather how deliberately each librarian incorporates [the steps of research] into routine work habits" (2000, p. 85). This is an important point. Because of standards for tenure and promotion, librarians are required to do research and disseminate it for career advancement. With practitioner-researchers, it goes further than that. Research is done to inform practice, to improve decision-making, to make sense, and to satisfy curiosity. Mitchell, Lunt, and Shaw propose that "practitioner-researchers occupy a hybrid culture that is neither practitioner nor researcher" (2010, p. 20). I can accept the notion of a hybrid culture, but instead of saying neither practitioner nor researcher, I would suggest that we are both practitioner and researcher. The dual role can allow us to practice with much fuller knowledge of our work.

\section{Why is the Practitioner-Researcher Necessary in Librarianship?}

In his book The practitioner-researcher: developing theory from practice, Peter Jarvis states that "practitioner-researchers are able to report aspects of practice at a depth that traditional forms of research might well not capture, precisely because they are practitioners" (24).

Because so much of our decision-making deals with issues of a practice nature, having a recognized body of research from the practitioner perspective would be an addition and an enhancement to the scholarly LIS literature available. A professional dialogue in the research literature between LIS scholars and practitioners would add robustness to the research conducted by both parties, which would serve to augment the outputs from both as well.
In healthcare, Yanos and Ziedonis have concluded that "patient-oriented clinicianresearchers can serve as effective 'bridgers' between the research and practice communities and can facilitate both the development of clinically relevant research and the dissemination of evidence-based treatments into routine clinical services" (2006, p. 253). Translated into LIS, the librarian practitioner-researcher could perform that same bridging role between the two camps of librarians: the scholars and the practitioners. The two authors also observe that "it is often stated that the field [of medicine] would stagnate without the involvement of researchers who have direct clinical experience with the health conditions and the service systems being studied" (Yanos \& Ziedonis 2006, p. 259). In support of that thought, McGowan and Dow claim that "no discipline can advance without a research agenda, and academic librarians are in a unique position to do research" (1995, p. 349).

\section{The Perceived Legitimacy of the Role}

Are practitioner-researchers "real" researchers? A prominent complaint about some publications in librarianship is that there are very many cases of the "how we done it good" papers: authors engage in superficial description without looking at the larger context or doing much analysis. This does not only occur in librarianship. Brooker and MacPherson observe in a paper focused on the educational field that they have seen "a proliferation of personal experiences and recollections of past occurrences which are being promoted under the banner of research (1999, p. 218). They go on to state that in order to be taken seriously, "practitioner researchers must have a sense of responsibility to think clearly in terms of purposes for the research, modes of research investigation, ways of documenting research strategies and outcomes, and ways of interpreting these outcomes and drawing implications for further action and investigation" Brooker \& MacPherson (1999, p. 210). In other words, practitioner-researchers must conduct and report on "real" research, that is, a systematic investigation of a question or an issue using 
definable methodology and leading to a conclusion. However, it must be noted that practitioner-researchers seek "to understand, rather than control, the conditions in which practice occurs" (Jarvis, 1999, p. 99). Jarvis states that "the practitioner-researchers' own practice is unique, so the findings from practice situations cannot be applied to other situations" (1999, p. 84). I would argue that, while technically Jarvis may be correct, finding evidence from a practice that is similar to your own would yield benefits nonetheless.

\section{The Disciplines}

The practitioner-researcher model is found in many disciplines, including nursing, social work, and education. I will speak a bit about each of these disciplines, although the review of the literature in all cases is representative rather than exhaustive.

\section{Nursing}

Evidence based nursing practice has placed building research capacity front and centre in the UK (Deave, 2005). Jarvis, in his article about practitioner-researchers in nursing, has stated that "practice has become a site for learning" (2000, p.33). Due to the fast pace and transitory nature of practice, "every practice situation has become a potential research situation" (Jarvis, 2000, p.32). Literature about research in nursing observes that while nurses are encouraged to use the research evidence to inform their practice, the problem is that the evidence is lacking when it comes to practice situations (Closs, 2000). Various programs have been put in place to encourage practising nurses to do meaningful research which is based in practice, but the usual barriers of time, research skills, and management buy-in are at play here as well. The call here is for further research training, facilitation between practice and research, and more grant funds for this type of research in practice in order to build research capacity. As well, nurses need to believe that their own distinct contributions have value (Wilson-Barnett, 2001). In terms of role conflict, the tension between the roles of practising nurse and researcher, a study undertaken by Deave around job advertisements for the research nurse position, suggests that the research nurse often works away from practice and only has contact with patients in the researcher role. This distance from caring practice runs contrary to the underpinnings of nursing, and "the researcher may be left feeling unsatisfied at being unable to help the individual" (Deave, 2005, p. 653). In Australia, the need has been recognized for clinical researchers. One program has three interesting aims: to support clinical research "with potential to lead to improved health outcomes"; to "foster training of clinical researchers, particularly those with a capacity for independent research"; and to "ensure effective translation of research outcomes" (Brown \& Sorrell, 2009, 628).

\section{Social Work}

Ian Shaw asks an interesting question about the research being done by practitionerresearchers: "Is practitioner research simply a street market version of mainstream research, or is it a distinct genre of research?" (2005, p.1231). This hearkens back to the perceived legitimacy of the role. Is it real or is it a knock off? McCrystal has written about a study he did on a practitioner research training program for social workers in the UK, and has stated that "practitioner research does not entail any particular method or strategy of research, and is not in itself a special category of research" (2000, p. 361). He goes on to say that to be credible, social work research much be undertaken with the same rigorous standards in terms of methodology and interpretation that should be found in social science research. In his study, McCrystal found that $99 \%$ of the social workers surveyed "believed that research could be an asset to professional practice" but that only 7 respondents suggested that they themselves become actively involved in undertaking research (2000, p. 364 and 366).

\section{Education}

In Education, practitioner research is often termed action research, and the practitionerresearcher has been around the teaching profession for quite a few years, emerging in 
the UK in the 1960s (Elliott, 1990, p. 1).

However, there has been resistance to legitimizing practitioner research in education by the academic community (Anderson \& Herr, 1999). School-based inquiry by teachers has been marginalized as a form of teacher development but not recognized as a form of knowledge production (Zeichner, 1995, p. 153). Throughout the literature, there is agreement about the satisfaction of engaging in inquiry about their own practice that is garnered by teachers. Being teacher-researchers helps teachers better understand their own practice. They become resources for others, they begin to read in a critically responsive way, and they collaborate with students to answer the questions that are important to both groups (Cochran-Smith \& Lytle, 1990, p. 8).

\section{Practical Issues}

\section{Finding Time for Research}

I work in academic librarianship in Canada, where the standards for tenure and promotion include a research component. I was attracted to academic librarianship, as I know some of my colleagues were, because of the research piece. The opportunity to conduct research in an academic setting as well as to practise as a librarian is attractive. As members of the University Faculty, librarians are required to develop a program of research in order to achieve tenure and to make our way up through the ranks. Our Guidelines for Assignment of Duties acknowledges this requirement by quantifying the time we should spend on research endeavours: $20 \%$ of our work assignment for pre-tenured librarians, and $15 \%$ of our assignment once tenure has been achieved. It can be a challenge to combine a research program with one's daily job responsibilities. The fact that it is a requirement motivates academic librarians to follow the practitioner-researcher route.

Librarians in other sectors or countries will not necessarily have this motivation and their time challenges will be more daunting.

\section{Support: Financially and from Management}

When librarians do research on an ad hoc basis, often the standardized supports are not there. Financial concerns and lack of support from management can hamper one's best intentions. It can take a while for the buy-in to occur in an organization. One way to achieve buy-in is to show the value of the research being done.

\section{Role Conflict}

One of the issues around being a practitioner who does research is role conflict. Ethical conflicts, especially in the health field, are a large cause of confusion and role conflict. There can be tension between the roles, or as Yanos and Ziedonis state, "...confusion or conflict that often occurs when an individual functions in multiple roles simultaneouslytermed 'interrole conflict' by social psychologists" (2006, p. 251).

\section{Balancing Quality with Utility}

The research we do has to be useful. Additionally, it should be of a standard that allows others to use it too. With constraints like timelines and support issues, there may be the feeling that while the research undertaken can inform our own individual and subjective practices, we might feel hesitant to disseminate it. So, there must be a focus on balancing quality with utility in order to make the best use of the research. There are methodological solutions, but they will not work in all circumstances. There could be replications of studies, synthesis of studies, and perhaps multicentre collaborations to get more generalizable results.

\section{Next Steps}

- Determine the needs of practitionerresearchers so they can be better supported.

- Focus on effective dissemination of research findings so they are accessible and usable by practitioners.

- Urge LIS educators to incorporate more practitioner research into the curriculum to expose students to the wide variety of research and research 
possibilities that are available to them as practitioners.

\section{Conclusion}

Standing on the line between scholar and practitioner, the librarian practitionerresearcher is in a distinctive position to examine closely and to test issues of a practice nature from a unique perspective. Lawrence Stenhouse once said that "It is teachers who, in the end, will change the world of the school by understanding it." (quoted in Johnson, 1993).

The field of librarianship must have practitioner-researchers who can participate in changing the world of the library by understanding it. The output of these researchers must be positioned in such a way in the body of LIS research so that maximum benefit can be derived from this type of practical research. Mitchell, Lunt, and Shaw state for social work that "for the impact of practitioner research studies to be maximized there should be a broad-based dissemination strategy" (2010, p.22) and that practitioner research should be "promoted as a means to stimulate research- mindedness and capacity" (2010, p. 21). The same can be said for librarianship. Practical research undertaken from within the space of an intellectual discipline will provide well-rounded and robust evidence to the field. Peter Jarvis stated that "research is now not removed from the daily round of practice: it is being demystified and democratized. It is being undertaken, to a great extent but not exclusively, by practitioners, a trend that should grow and develop in this age of learning" (2000, p. 35). The presence of librarian practitionerresearchers is crucial if evidence based library and information practice is to move forward in a practical as well as theoretical way.

\section{References}

Anderson, G. L. \& Herr, K. (1999). The new paradigm wars: Is there room for rigorous practitioner knowledge in schools and universities? Educational Researcher, 28(5), 12-40. doi:10.3102/0013189X028005012
Bentz, V. M. \& Shapiro, J. J. (1998). Mindful inquiry in social research. Thousand Oaks, CA: Sage Publications.

Brooker, R. \& MacPherson, I. (1999). Communicating the processes and outcomes of practitioner research: An opportunity for self-indulgence or a serious professional responsibility? Educational Action Research, 7(2), 207221. doi:10.1080/09650799900200088

Brown, G. V. \& Sorrell, T.C. (2009). Building quality in health - the need for clinical researchers. The Medical Journal of Australia, 190(11), 627-629.

Closs, J. (2000). Research for nursing: Whose job is it anyway? Nurse Education Today 20(6) 423-425.

doi:10.1054/nedt.2000.0500

Cochran-Smith, M. \& Lytle, S.L. (1990). Research on teaching and teacher research: The issues that divide. Educational Researcher, 19(2), 2-11. doi:10.3102/0013189X019002002

Crumley, E. \& Koufogiannakis, D. (2002). Developing evidence-based librarianship: Practical steps for implementation. Health and Information Libraries Journal, 19(2), 61-70. doi:10.1046/j.1471-1842.2002.00372.x

Deave, T. (2005). Research nurse or nurse researcher: How much value is placed on research undertaken by nurses? Journal of Research in Nursing, 10(6), 649-657. doi:10.1177/174498710501000608

Elliott, J. (1990). Teachers as researchers: Implications for supervision and for teacher education. Teaching \& Teacher Education, 6(1), 1-26. doi:10.1016/0742051X(90)90004-O

Jarvis, P. (1999). The practitioner-researcher: Developing theory from practice. San Francisco, CA: Jossey-Bass. 
Jarvis, P. (2000). The practitioner-researcher in nursing. Nurse Education Today, 20(1), 30-35. doi:10.1054/nedt.2000.0428

Johnson, B. (1993). Teacher-as-researcher. ERIC Clearinghouse on Teacher Education. Accessed Feb 25, 2013. http://www.ericdigests.org/1993/resear cher.htm

McCrystal, P. (2000). Developing the social work researcher through a practitioner research training program. Social Work Education, 19(4), 359-373. Doi: 10.1080/02615470050078366

McGowan, J.J. \& Dow,E.H. (1995). Faculty status and academic librarianship: Transformation to a clinical model. The Journal of Academic Librarianship, 21(5), p. 345-350. doi: 10.1016/0099-1333(95)90059-4

Mitchell, F., Lunt, N., \& Shaw, I. (2010). Practitioner research in social work: A knowledge review. Evidence \& Policy, 6(1), 7-31.

Research_is_formalized_curiosity_It_is_poking _and. (n.d.). Columbia World of Quotations. Retrieved March 04, 2013, from Dictionary.com website: http://quotes.dictionary.com/Research is formalized curiosity It is poking and
Shaw, I. (2005). Practitioner research: Evidence or critique? British Journal of Social Work, 35(8), 1231-1248. doi:10.1093/bjsw/bch223

Watson-Boone, R. (2000). Academic librarians as practitioner-researchers. The Journal of Academic Librarianship, 26(2), 85-93. doi:10.1016/S0099-1333(99)00144-5

Wilson-Barnett, J. (2001). Research capacity in nursing. International Journal of Nursing Studies, 38, 241-242.

Yanos, P. T. \& Ziedonis, D.M. (2006). The patient-oriented clinician-researcher: Advantages and challenges of being a double agent. Psychiatric Services 57(2): 249-253. doi: 10.1176/appi.ps.57.2.249

Zeichner, K. M. (1995). Beyond the divide of teacher research and academic research.

Teachers and Teaching: Theory and Practice, 1(2), 153-172. doi: 10.1080/1354060950010202 